\title{
Photocurable Bioadhesive Based on Lactic Acid
}

D. S. Marques ${ }^{a}$, J. M. C. Santos ${ }^{a}$, P.Ferreira ${ }^{a}$, T. R. Correia ${ }^{b}$ I. J. Correia ${ }^{b}$, M. H. Gil ${ }^{a}$, C. M. S. G. Baptista ${ }^{a, *}$

' CIEPQPF, Department of Chemical Engineering, University of Coimbra, P-3030 790 Coimbra,

Portugal

${ }^{\mathrm{b}}$ CICS-UBI, Health Sciences Research Center, University of Beira Interior,P-6200 506 Covilhã,

Portugal

*Corresponding Author: Email address is: cristina@eq.uc.pt

Tel: +351-239798700. Fax: +351-239798703 


\section{ABSTRACT}

Novel photocurable and low molecular weight oligomers based on L-lactic acid with proven interest to be used as bioadhesive were successfully manufactured. Preparation of lactic acid oligomers with methacrylic end functionalizations was carried out in the absence of catalyst or solvents by self-esterification in two reaction steps: telechelic lactic acid oligomerization with $\mathrm{OH}$ end groups and further functionalization with methacrylic anhydride. The final adhesive composition was achieved by the addition of a reported biocompatible photoinitiator (Irgacure ${ }^{\circledR}$ 2959). Preliminary in vitro biodegradability was investigated by hydrolytic degradation in PBS $(\mathrm{pH}=7.4)$ at $37^{\circ} \mathrm{C}$. The adhesion performance was evaluated using glued aminated substrates (gelatine pieces) subjected to pull-to-break test. Surface energy measured by contact angles is lower than the reported values of skin and blood. The absence of cytoxicity was evaluated using human fibroblasts. A notable antimicrobial behaviour was observed using two bacterial models (S. aureus and E. coli). The cured material exhibited a strong thrombogenic character when placed in contact with blood, which can be predicted as haemostatic effect for bleeding control. This novel material was subjected to an extensive characterization showing great potential for bioadhesive or other biomedical applications where biodegradable and biocompatible photocurable materials are required.

Keywords: Bioadhesive Formulation, Telechelic Lactic Acid Prepolymers, Photocurable, Polycondensation, Biocompatibility 


\section{Introduction}

The use of bioadhesives for human tissue regeneration has received an increasingly acceptance as an alternative to suturing. Bioadhesives can be used in internal or external lacerations and surgical incisions allowing a fast, easy and non-invasive procedure and can be applied where suturing is not possible. Moreover, they can be designed to prevent the occurrence of infection by performing as a barrier for external risk factors, or for localizeddrug release,increasing the overall healing process efficiency [1-3].

Bioadhesives must exhibit different properties according to targeted tissues and the risk factors involved [4]. The clinical applications depend on their physical-chemical properties and activation method: chemical or light [5]. Haemostatic properties and mechanical strength are important in vascular surgery. Strong adhesion to skin or to wet tissues, particularly in internal organs, is necessary for many surgical procedures. All these features must be taken into consideration when designing new adhesive formulations for specific needs. However, suitable surgical adhesives require some common features such as adequate viscosity prior to application, easy adhesion to the damaged tissues, strong closure throughout the healing process and degradation into non-toxic products when no longer needed. A fast curing under physiological conditions, without releasing heat, is an important requisite for photocurable surgical adhesives [1-6].

Currently approved surgical glues, which are based on fibrin and cyanoacrylates, have been associated with some safety issues, being fibrin glues generally less toxic [4]. Fibrin presents risk of blood transmitted diseases and cyanoacrylates are reported to degrade into formaldehyde [16]. Recent advances have been studied using polysaccharides [7-9] or man-made materials such as PEG-based adhesives. Overall, they tend to increase the swelling after in vivo application, 
leading to a decrease in mechanical strength and thus hampering a good adhesion [10]. Other studies are related to mussel inspired adhesives. Biomaterials modification with catechol compounds extracted from mussel proteins is reported to improve adhesion bond strength in wet surfaces [11-13]. However, practical applications have been hindered by uneconomical extraction processes and unsuccessful large scale production. Thus, efforts to develop non-toxic, biodegradable, haemostatic, biocompatible, short curing time, good adhesiveness and commercially viable bioadhesives remain a challenge.

Several studies have already been conducted aiming at developing a bioadhesive that fulfils the previously described requirements $[1-3,14-17]$. Synthetic aliphatic polyesters with photocrosslinkable groups have shown good adhesion results and a fast-curing rate at physiological temperature. These features, together with the ester bond hydrolytic and enzymatic degradation ability, make them promising materials to be exploited in temporary surgical applications $[1-3,18]$. A biodegradable polyester largely used in the biomedical industry is poly(lactic acid) (PLA). It has been used in biodegradable sutures, scaffolds, clamps and controlled release devices [19]. However, its use as a bioadhesive has not been properly studied since commercial PLA has high molecular weight, high glass transition temperature and low solubility in non-toxic solvents, which prevent its straight use as a tissue adhesive.

Helminen et al. [14] reported the synthesis of star lactide based prepolymers by ring opening polymerization (ROP) in the presence of pentaerythritol as initiator, followed by modification with methacrylic anhydride (MAA) and further thermal crosslinking at $90{ }^{\circ} \mathrm{C}$. Nevertheless, the resulting material showed a relatively high glass transition temperature, unsuitable for bioadhesive applications. Karikari et al. [19] reported the synthesis of 4-arms star-shaped polylactide end functionalized either with methacrylic anhydride or with 2-isocyanatoethyl 
methacrylate cured by photopolymerization with 2,2-dimethyl-2-phenylacetophenone as the radical photoinitiator. Since the molecular weights of these prepolymers were higher than 2000 g.mol ${ }^{-1}$, resulting in a glassy solid at room temperature, chloroform was used as solvent, a totally unsuitable formulation for human use according to the International Conference on Harmonisation-ICH guidelines [20]. Although their syntheses were intended for bioadhesive application no biocompatibility assessment was reported and the authors focused only on chemical, thermal and mechanical characterization [19]. Ho et al. [21] studied the synthesis of poly(lactide-propylene glycol) dimethacrylate adhesives but, again, biocompatibility was not investigated. Moreover, ring opening polymerization of lactide, as well as other lactones, requires a tin based catalyst which has been reported as a source of toxicity in brain and nervous tissues and to cause DNA damage [21]. Common purification technique by solvent precipitation is not effective to remove tin catalysts since they remain partially coordinated to the polymer end functionality [22-24].

Following a three reaction steps approach, without requiring the addition of catalysts or organic solvents, a new strategy to produce photocrosslinkable bioadhesives from lactic acid as main building block is reported here. Telechelic lactic acid prepolymer with low molecular weight was synthesized by self-condensation, subsequently modified with double bonds and further photocrosslinked under ultraviolet (UV) exposure in the presence of a radical photoinitiator. Irgacure ${ }^{\circledR} 2959$ was used as the photoinitiating agent since it was proved to be well tolerated over a wide range of cell types and chemical concentrations [25] and has been successfully used in the biomaterials filed by several authors [26-28].

In order to assess its potential for bioadhesive applications, the resulting material was subjected to a quite extensive chemical, thermal, mechanical and biocompatibility characterization.The low 
molecular weight of the oligomers allows their application as a viscous liquid. It is also possible to increase the double bonds density, essential for attaining fast curing rates in situ under mild conditions $[21,29]$. This study has shown that conventional polycondensation can be envisaged as a promising mechanism for the production of tailor-made materials for targeted needs in the biomedical field.

\section{Experimental}

\subsection{Materials}

Materials were purchased from Sigma-Aldrich, Acros or Chem-Lab and used without further purification: aqueous solution of $\mathrm{L}(+)$-lactic acid (80 \%), 1,4-butanediol (BD) (99\%), methacrylic anhydride (MAA) (94\%), diethyl ether (99\%), ethylene glycol (99.8\%), formamide (99\%), propylene glycol (99.5\%), potassium ferrocyanide (99\%), formaldehyde (37\%, stabilized with methanol), non-ionic surfactant Triton $\mathrm{X}^{\circledR}-100$, Dulbecco's modified Eagle’s medium (DMEM-F12), ethylenediaminetetraacetic acid (EDTA), LB Broth, Kanamycin, phosphatebuffered saline solution (PBS), Streptomycin and Trypsin.

Irgacure $^{\circledR} 2959$ (97 - $99 \%$ ) was kindly provided by BASF and used as a radical photoinitiator. Fresh rabbit blood with an anticoagulant (ACD-blood) was purchased from Probiológica to be used in thrombogenic studies. Criopreserved human fibroblasts cells, passage number 20 (P20), used in cytotoxicity experiments, were acquired from PromoCell. Bacterial strain Escherichia coli (E.coli) DH5a ${ }^{\mathrm{TM}}$ (18263-012) were purchased from Invitrogen and Staphylococcus aureus (S. aureus) (25923) were purchased from ATCC and used to evaluate the antibacterial behavior of the produced film. Fetal bovine serum(FBS), Biochrom and 3- (4,5-dimethylthiazol-2-yl) -5- 
(3-carboxymethoxyphenyl) -2- (4-sulfophenyl) -2H-tetrazolium (MTS), Promega, were also used for biocompatibility studies.

2.2.Synthesis of telechelic lactic acid prepolymers

L-Lactic acid (80\%) aqueous solution $(100 \mathrm{~mL})$ and $16 \mathrm{~mL}$ of the co-monomer, 1,4-butanediol, were placed in a neck round-bottom glass flask, equipped with a magnetic stirrer and a glass condenser, and allowed to react at $150{ }^{\circ} \mathrm{C}$ under nitrogen stream. When no more water was removed (around $9 \mathrm{~h}$ of reaction) the process was stopped by removing the reaction flask from the thermic oil heating bath and the product stored in a dry and cold place for further functionalization. The amount of co-monomer introduced (0.179 moles) was calculated according to the target oligomer molecular weight in Table 1.

\subsection{Prepolymers functionalization with methacrylic anhydride}

In a $100 \mathrm{~mL}$ round bottom flask immersed in an oil bath, methacrylic anhydride (MAA) was added to 0.01 mole of lactic acid based prepolymer. The molar ratio was 1 mole of MAA per 2 moles $\mathrm{OH}$ end groups, considering that the methacrylic acid resultant of the anhydride reaction is also consumed. The reaction was allowed to proceed for $24 \mathrm{~h}$ at $130^{\circ} \mathrm{C}$, under stirring and nitrogen stream. The temperature and the reaction time were determined by the decision not to add a catalyst to this esterification reaction, and above usual values for these parameters. The functionalized oligomer thus obtained is further referred as macLA-MAA. This product was stored in a flask protected from light, which was placed in a cool dark environment. 
2.4.Synthesis of networks by UV irradiation

Irgacure ${ }^{\circledR} 2959$ in a percentage of $6 \%$ of the carbon double bonds moles, previously dissolved in $20 \mathrm{~mL}$ of diethyl ether, was added to the modified prepolymer, macLA-MAA, at $60{ }^{\circ} \mathrm{C}$ and stirred under reflux until a homogeneous solution was obtained. This solution was poured onto a Petri dish, or coated over a glass plate using a stainless steel cylinder to control the thickness, and then irradiated for 2 min until well defined and uniform films were obtained. The UV lamp was a Multiband UV UVGL-48 model from Mineral Light (wavelength of 254-354 nm). Finally, films (referred as netLA-MAA) were dried under vacuum conditions to remove the remaining diethyl ether and characterized.

\subsection{Characterization Techniques}

2.5.1. Attenuated Total Reflectance - Fourier Transform Infrared Spectroscopy (ATR-FTIR) ATR-FTIR was used for identification of the reactions products. Spectra were recorded on a Jasco FT/IR-4200 Spectrometer equipped with a Golden Gate Single Reflection Diamond ATR on an average of 128 scans at a resolution of $4 \mathrm{~cm}^{-1}$.

\subsubsection{Nuclear Magnetic Resonance (NMR)}

The ${ }^{1} \mathrm{H}$ NMR spectra of the oligomers in $\mathrm{CDCl}_{3}$ solvent, at room-temperature, were obtained on a Varian Unity $500 \mathrm{MHz}$ spectrometer. Samples were prepared by dissolving $10 \mathrm{mg}$ of oligomers in $600 \mu \mathrm{L}$ of the deuterated solvent. 


\subsubsection{Thermal Analysis}

Dynamical Mechanical Thermal Analysis (DMTA) of $\approx 0.2 \mathrm{~mm}$ thick specimens was performed using a Triton Tritec 2000 in the Single Cantilever Bending mode and in multifrequency conditions $(1,10 \mathrm{~Hz})$ with a standard heating rate of $5^{\circ} \mathrm{C} \cdot \mathrm{min}^{-1}$. The glass transition temperature ( $T g$ ) was determined as the peak in $\tan \delta\left(\tan \delta=\mathrm{E}^{\prime}, \mathrm{E}^{\prime}\right)$, where E', and E' are the loss and storage modulus, respectively. The specimen was cut from the film obtained from photocrosslinking as explained above.

The Thermogravimetric Analysis (TGA) was carried out in a SDT Q500 from Thermal Analysis Instrument at a heating rate of $10{ }^{\circ} \mathrm{C} \cdot \mathrm{min}^{-1}$ with a nitrogen flow rate of $100 \mathrm{~mL} \cdot \mathrm{min}^{-1}$.

\subsubsection{Hydrolytic Degradation in phosphate buffer solution}

Film specimens ( $1 \mathrm{~mm}$ and $2 \mathrm{~mm}$ of thick) were placed in bottles containing $10 \mathrm{~mL}$ of a phosphate buffer solution (PBS) (0.01M; pH 7.4) and subjected to hydrolytic degradation at 37 ${ }^{\circ} \mathrm{C}$ up to42 days. Three samples were removed at predetermined times and the buffer solutions of the remaining bottles were replaced. After degradation the films were washed with fresh water and dried until constant weight. The degree of degradation was estimated from the weight loss, which was calculated using the following equation:

Weight $\operatorname{loss}(\%)=\frac{\left(W_{0}-W_{d}\right)}{W_{0}} \times 100(1)$

where $W_{0}$ and $W_{d}$ are the average weight of the three specimens before and after the degradation.

\subsubsection{Swelling in Saturated Atmosphere}

Dried samples of crosslinked film were weighted $(W d)$ and placed in a container with a saturated solution of pentahydrate copper sulphate at room temperature. Specimens of each sample were 
removed and weighted at predetermined times $(W s)$ until maximum weight was achieved. Experiments were carried out in triplicate. The swelling ratio was evaluated using the following equation:

Swelling ratio $(\%)=\frac{(W s-W d)}{W d} \times 100$

\subsubsection{Mechanical Performance}

In order to evaluate the bonding performance of the photocrosslinkable lactic acid oligomers, a viscous formulation containing the photoinitiator was spread between gelatine strips (dimensions $1.5 \mathrm{~cm} \times 3 \mathrm{~cm}$ ). The gelatine pieces containing the adhesive formulation were overlapped (active area $1.5 \mathrm{~cm} \times 1 \mathrm{~cm}$ ) and then irradiated under the same conditions (2min) described for the synthesis of the crosslinked networks obtaining a test specimen with total dimensions of $1.5 \mathrm{~cm} \times 5 \mathrm{~cm}$. Those test strips were then subjected to the pull-to-break test at room temperature using an Instron $5900 \mathrm{R} 1186$. The pulling velocity was set as $5 \mathrm{~mm} \cdot \mathrm{min}^{-1}$, and the distance between the probes was $1 \mathrm{~cm}$. The software program coupled to the apparatus recorded the force and length variation. The tests ended with the fracture of the gelatine pieces or their separation in case adhesion failed to occur. A strip of the original gelatine sheet $(1.5 \mathrm{~cm} \times 5 \mathrm{~cm})$ was also subjected to the same test in order as a control.

\subsubsection{Determination of surface energy by contact angle measurements}

Surface tensions of the produced films were evaluated by static contact-angle measurementsin an OCA 20 equipment from Dataphysics. The tests were performed on the air-facing surface of the samples with four liquids: water, formamide, ethylene glycol, and propylene glycol by the sessile drop method at room conditions.Ten measurements on different points were carried out to 
calculate the mean static contact angle and the standard deviation. The surface energy $\left(\gamma_{S}\right)$, as well as their dispersive $\left(\gamma_{S}^{D}\right)$ and polar $\left(\gamma_{S}^{P}\right)$ components, of the cured adhesive were determined according to the well-established Owens-Wendt-Rabel and Kaelble (OWRK) method [3].

\subsubsection{Thrombogenicity}

The evaluation of thrombus formation on three films surfaces was carried out using the gravimetric method originally reported by Imai and Nose (1972) [3]. For this purpose anticoagulated rabbit blood (ACD-A blood) was used, as received. Before performing the tests, the films were immersed inPBS solution ( $\mathrm{pH} 7.4)$ at constant temperature $\left(37^{\circ} \mathrm{C}\right)$. After $24 \mathrm{~h}$ incubation, the PBS was removed and $250 \mu \mathrm{L}$ of ACD blood were placed in contact with the surface of the polymers and also with an empty glass Petri dish, used as a positive control. Blood clotting tests were initiated by adding $25 \mu \mathrm{L}$ of a $0.1 \mathrm{M}$ calcium chloride solution and were stopped 40 min later by the adding $5 \mathrm{~mL}$ of distilled water.The resultant clots were fixed with $5 \mathrm{~mL}$ of a $37 \%$ formaldehyde solution, dried at $37^{\circ} \mathrm{C}$ for $24 \mathrm{~h}$ and finally weighted.

\subsubsection{SEM evaluation of cell adhesion and proliferation on materials surface}

The materials morphology with/without human fibroblast cells were assessed by SEM technique. To evaluate cell adhesion and proliferation, human fibroblast cells $\left(2 \times 10^{4}\right.$ cells/well $)$ were seeded over the sterilized materials in 48 -well plates for $72 \mathrm{~h}$. The samples were fixed overnight with $2.5 \%$ glutaraldehyde in $\mathrm{PBS}$, at $4^{\circ} \mathrm{C}$ and then frozen in a glass container using liquid nitrogen and freeze-dried for $3 \mathrm{~h}$. Finally, the films were mounted on an aluminium board using a double-sided adhesive tape and covered with gold using a Quorum Q150R ES sputter coater. The 
samples were then analyzed using a Hitachi S-3400N scanning electron microscope operated at an accelerating voltage of $20 \mathrm{kV}$ and at different magnifications [30,31].

2.5.10. Characterization of the cytotoxic profile of the films using human fibroblasts cells Human fibroblasts cell culture was achieved as described in literature [32]. Cell behaviour in the presence of the materials was then evaluated, by seeding the fibroblasts cells with materials in 96-well plates at a density of $1 \times 10^{4}$ cells per well, for $72 \mathrm{~h}$. Previously to cell seeding, materials were firstly sterilized using UV radiation for $30 \mathrm{~min}$. Cell growth was monitored using an Olympus CX41 inverted light microscope equipped with an Olympus SP-500 UZ digital camera [33]. Afterwards, the cytotoxic profile of netLA-MAA material was assessed as previously described [34]. Concisely, human fibroblasts cells were seeded in the presence of materials, in 96-well plate with $100 \mu \mathrm{L}$ of DMEM-F12, followed by incubation at $37^{\circ} \mathrm{C}$, in a $5 \% \mathrm{CO}_{2}$ humidified atmosphere. After an incubation period (24, 48 and $72 \mathrm{~h})$, cell viability was assessed through the reduction of the MTS into a water-soluble formazan product. Briefly, the medium of each well was removed and replaced with a mixture of $100 \mu \mathrm{L}$ of fresh culture medium and 20 $\mu \mathrm{L}$ of MTS reagent solution. Then, cells were incubated for $4 \mathrm{~h}$ at $37^{\circ} \mathrm{C}$, under a $5 \% \mathrm{CO}_{2}$ humidified atmosphere. The absorbance was measured at $492 \mathrm{~nm}$ using a microplate reader (Sanofi, Diagnostics Pauster). Wells containing cells in the culture medium without materials were used as negative controls $\left(\mathrm{K}^{-}\right)$. Ethanol (96\%) was added to wells that contained cells, as a positive control $\left(\mathrm{K}^{+}\right)$. 
2.5.11. Characterization of the antibacterial activity of netLA-MAA films

To assess biofilm formation on the netLA-MAA materials surfaces, E.coli and S.aureus were seeded over them at $1 \times 10^{8} \mathrm{CFU} \mathrm{mL}{ }^{-1}$ in an agar plate. After $24 \mathrm{~h}$, the materials were prepared for SEM analysis [35].

\section{Results and Discussion}

\subsection{Bioadhesives Synthesis}

Telechelic prepolymers with low molecular weight were synthesised by direct thermal dehydration of L-lactic acid in the presence of 1,4-butanediol as co-monomer, obtaining a linear hydroxyl terminated prepolymer referred from now on as oligLA. Then photoreactive sites were introduced into the $\mathrm{OH}$ terminal groups by functionalization with methacrylic anhydride (MAA). The resultant modified prepolymer (macLA-MAA) showed a viscous oily appearance, with potential for in situ injectable use. All these reactions are catalyst and solvent free.

Well defined and uniform crosslinked films were obtained by photopolymerization under UV irradiation in the presence of Irgacure ${ }^{\circledR} 2959$ as photoinitiating agent in a percentage of $6 \%$ of the introduced carbon double bonds. This ratio was chosen after a preliminary assessment to set curing time within few minutes [17]. Irgacure ${ }^{\circledR} 2959$ was found to be rather insoluble in the viscous oligomer requiring a prior solubilisation in diethyl ether before being introduced into the prepolymer flask. A schematic representation of the prepolymer synthesis, functionalization and curing reactions is shown in Fig. 1.

(Fig. 1)

The information related to the target molecular weight, curing time required for a self-supporting membrane, glass transition temperature $(T g)$ and water sorption ability are presented in Table 1 . 
${ }^{1} \mathrm{H}$ NMR and FTIR spectroscopies were used to follow the reactions during this study and to assess the chemical structure of the telechelic lactic acid oligomers and subsequent functionalization product. The ${ }^{1} \mathrm{H}$ NMR spectrum of the telechelic lactic acid oligomers (oligLA) is shown in Fig. 2 (bottom) and the spectrum of the functionalized oligomers (macLA-MAA) is shown in Fig. 2 (top). The first remarkable observation in the bottom spectrum is the absence of the typical chemical shifts at $4.03 \mathrm{ppm}$ and $1.23 \mathrm{ppm}$ assigned in the literature to the $\mathrm{CH}$ and $\mathrm{CH}_{3}$ protons of the lactic acid starting monomer $[36,37]$. The spectrum exhibited two additional resonances at $3.72 \mathrm{ppm}$ due to the introduction of $\mathrm{CH}_{2}$ protons in the molecular structure from the co-monomer. The high number of signals due to the neighbouring effect makes difficult the identification of every signal and is a clear indication of the presence of low molecular weight oligomers. However, the peaks from 4.16 to $4.42 \mathrm{ppm}$ are assigned to the end $\mathrm{CH}$ protons whereas from 5.04 to $5.28 \mathrm{ppm}$ are assigned to the repeating units[19]. According to Karikari et al. [19] the resonances of the $\mathrm{CH}_{2}$ protons were compared to the $\mathrm{CH}$ repeating units to obtain a polymerization degree around 6 , which corresponds to a number-average molecular weight of 630 g. $\mathrm{mol}^{-1}$. This value is slightly higher than the target value which was calculated on the assumption of the equal reactivity of the hydroxyl groups in the 1,4-butanediol co-monomer.

The lactic acid oligomers were successfully modified with MAA to introduce terminal photoreactive sites as can be observed in Fig. 2 (top). The ${ }^{1} \mathrm{H}$ NMR spectrum of macLA-MAA exhibited two new resonances at $5.64 \mathrm{ppm}$ and $6.21 \mathrm{ppm}$, assigned to the olefinic protons, and a new resonance at $1.97 \mathrm{ppm}$ from the $\mathrm{CH}_{3}$ methyl of the methacrylate end functionalities. Comparison of the integration of resonance at $3.72 \mathrm{ppm}$ with integrations of resonances at 5.64 ppm and $6.21 \mathrm{ppm}$ of the olefinic protons indicates a 78\% functionalization [19].

(Fig. 2) 
Similarly to the NMR, ATR-FTIR spectroscopy was used to monitor the prepolymer synthesis, functionalization and final crosslinking reactions. The FTIR spectra in Fig. 3 confirm the successful functionalization of telechelic lactic acid prepolymer with MAA and its subsequent photocrosslinking.

(Table 1)

(Fig. 3)

Carbon double bounds were introduced into the lactic acid prepolymers by reaction of its hydroxyl end groups with MAA. The presence of double bonds after functionalization was confirmed by the appearance of new bands at $1636 \mathrm{~cm}^{-1}$ and $813 \mathrm{~cm}^{-1}$ and by the decreasing intensity of the hydroxyl stretching peak at $3460 \mathrm{~cm}^{-1}$. No peak correspondent to anhydride bond was detected in the functionalized prepolymers. After UV irradiation the netLA-MAA spectra in Fig. 3 show the disappearance of the double stretching peaks due to crosslinking.

The curing time for effective crosslinking was defined as the time required to obtaining a welldefined and uniform membrane, while peaks assigned to the double bond in the ATR-FTIR disappeared. The result suggested that $2 \mathrm{~min}$ of UV exposure was enough to achieve a high degree of curing. It is important to underline that in resorbable systems for biological applications a complete conversion of the free double bounds must be accomplished to ensure that potentially reactive and toxic compounds are not released upon degradation.

\subsection{Thermal Properties}

DMTA technique was selected to identify the $T g$ of the synthesized material, since it has a higher sensibility to the $\alpha$-relaxation (glass to rubber transition) than the widespread DSC [19]. The experiments were carried out in the Single Cantilever Bending mode and in multifrequency (1, 
$10 \mathrm{~Hz}$ ) to allow a ready identification of the $\alpha$-transition. The DMTA traces at $1 \mathrm{~Hz}$ are shown in Fig. 4 and the recorded glass transition temperature taken from the $\tan \delta$ peak at $1 \mathrm{~Hz}$ was $1{ }^{\circ} \mathrm{C}$. The depicted $T g$ is lower than physiological temperature, therefore fulfilling an important requirement for the intended purpose, and no crystallization was observed.

(Fig. 4)

The thermal stability of the obtained film (netLA-MAA), the viscous adhesive formulation (macLA-MAA) as well as the oily appearance lactic acid prepolymer (oligLA) were assessed by TGA and the results are shown in Fig. 5. The results suggested that the weight loss of the lactic acid telechelic oligomers (oligLA) started around $80^{\circ} \mathrm{C}$, most probably due to volatilization of the remaining water in spite of previous drying, and continued till complete degradation at 240 ${ }^{\circ} \mathrm{C}$. Regarding the adhesive formulation (macLA-MAA) the weight loss started around $30{ }^{\circ} \mathrm{C}$, which roughly corresponded to the volatilization of the photoinitiator solvent, and continued to the main degradation stage until reaching the end around $380{ }^{\circ} \mathrm{C}$. The weight loss profile of the adhesive formulation points out for an improved thermal stability at high temperatures, comparing to the lactic acid prepolymers, being an additional evidence of double bonds successful functionalization.

The TGA trace of the crosslinked film showed a remarkable thermal stability improvement, reaching complete degradation at $440{ }^{\circ} \mathrm{C}$. However, the weight loss started at the same temperature as the lactic acid oligomers $\left(80^{\circ} \mathrm{C}\right)$. Besides water volatilization, the weight loss may also be ascribed to the release of low molecular weight compounds such as unreacted monomer or hydrolysis products. It is well known in the literature that UV cured polymers contain a certain amount of non-polymerized functional groups as well as residual photoinitiators and trapped radicals [38, 39] 
The presence of water in the initial lactic acid prepolymers and consequently in the adhesive formulation, even trace amounts, can promote hydrolysis reactions leading to the formation of low molecular products such as lactic acid and methacrylic acid, jeopardizing the formulation stability. Nevertheless, lactic acid is a natural occurring metabolite and methacrylic acid is a photocrosslinkable compound which ultimately also reacts by photopolymerization introducing carboxylic functionalities into the adhesive network. Therefore, hydrolysis side reactions should be taken into account when developing oligoesters formulation but is not perceived as a major drawback for the target application.

(Fig. 5)

\subsection{Swelling Ratio and Hydrolytic Degradation}

The results collected for the hydrolytic degradation in PBS solutions at $37^{\circ} \mathrm{C}$, presented in Fig.6, clearly demonstrate that crosslinked films preserve its hydrolytic instability, which is an essential requirement for short-term biomedical applications. Substantial weight loss occurs during the first days of immersion after which it continues more slowly. Some of the initial weight loss may be attributed to the diffusion of low molecules such as monomer or photoinitiator entrapped in the polymer network, corroborating the previous discussion on the thermal properties section 3.2. After 42 days immersion the samples lost around $40 \%$ of their initial weight.

The hydrolytic degradation of a lactic acid oligomer based network in aqueous solution is likely to proceed through random scission of the ester bond, being strongly accelerated by the slightly water absorption ability of the polymer matrix [40,41]. Polymer swelling is followed by volume increase. If a large change in volume occurs when placed in vivo may lead to damage of the surrounding tissues which prevents their use as a bioadhesive [3]. However, a moderate volume 
increase, as the one recorded in Table 1, may enhance the material haemostatic character throughout the healing process. Moreover, the water absorption is an indication of a certain hydrophilicity which may be a major contribution to the material biocompatibility.

As shown in Fig. 6, hydrolytic degradation of test specimens with different thickness (1 mm and $2 \mathrm{~mm}$ ) was investigated. Although the results depicted a similar degradation profile, thicker films showed a slightly but consistent higher weight loss. This result may be explained by diffusion constrains of the acidic degradation products from a thicker film into the surrounding medium. The accumulation of these degradation products further catalyses the hydrolysis reaction, increasing the hydrolysis rate.

(Fig. 6)

\subsection{Adhesive performance}

A preliminar assessement of the adhesive bond strength was carried out by applying a tensile force parallel to the adhesive overlaped joint until fracture took place. Commercial gelatine sheets present a great amount of amino groups in its compositions and therefore were chosen to simulate the composition of living tissues [3]. The adhesive formulation was placed between two gelatine piecess, irradiated with UV light for $2 \mathrm{~min}$ and then subjected to the strength test. A single strip of gelatine was tested as control and the fracture was recorded at $53 \mathrm{~N}$. For the glued gelatine the fracture happened at $50 \mathrm{~N}$ in one of the overlapped gelatine test specimens and not due to failure of the adhesive joint, showing promising results regarding mechanical performance of this new adhesive material. 
3.5.Determination of surface energy by contact angle measurement

Surface energy is an important parameter for driving or preventing adhesion between two surfaces. For an effective adhesion, the bonding agent cannot present a higher surface energy than the substrate. Contact angle of a liquid droplet on a solid substrate is widely recognized as a simple and quantitative method for defining the relative degree of interaction of a liquid with a solid surface [42]. In order to assess this parameter, contact angles were measured employing liquids with well-known surface tensions. The surface energy $\left(\gamma_{S}\right)$ as well as the dispersive $\left(\gamma_{S}^{D}\right)$ and polar $\left(\gamma_{S}^{P}\right)$ components of the cured adhesive were determined according to the OWRK method and compared with the reported values for skin and blood. The critical surface energy of skin can differ between 38 and $56 \mathrm{mN} . \mathrm{m}^{-1}$ depending on the measurement conditions, whereas the reported value for surface tension of blood is $47.5 \mathrm{mN} \cdot \mathrm{m}^{-1}$, at $37{ }^{\circ} \mathrm{C}[3,43]$.

The obtained surface tension of the netLA-MAA film was $37.83 \pm 5.28 \mathrm{mN} \cdot \mathrm{m}^{-1}$ with a dispersive component of $3.80 \pm 1.37 \mathrm{mN} . \mathrm{m}^{-1}$ and a polar component of $34.03 \pm 5.10 \mathrm{mN} . \mathrm{m}^{-1}$. This result showed that the surface energy values of skin and blood are higher than those of the cured film. Therefore, the adhesive forces between any of these surfaces and the produced adhesive are greater than the cohesive forces promoting intermolecular proximity. Consequently, adhesion between the lactic acid based adhesive and either skin or blood is likely to happen.

\subsection{Thrombogenicity}

The ability of thrombus formation on the surface of the adhesive film was assessed by gravimetry measurement after 40 minutes contact time, using a thrombogenic material as positive control (glass). Interestingly, the weight of resulting blood clots from the adhesive 
surface was found to be the same as in the positive control (100\%). This thrombogenic nature is directly connected to the low value of surface energy, discussed previously. Protein adhesion is reported as the first step of the coagulation cascade which ends in thrombus formation. When in contact with low surface energy materials, proteins adsorb strongly and irreversibly, promoting the formation of thrombus, and therefore explaining the thrombogenic character of this material. Regarding the target application as surgical adhesive, this thrombogenic character can be envisaged as a haemostatic effect being a major advantage for bleeding control [3, 43].

\subsection{Evaluation of cell viability and proliferation in the presence of netLA-MAA films} In vitro studies were performed using human fibroblasts as model cells since they are involved in human tissue regeneration [44]. Herein, cell adhesion and proliferation in the presence of the materials was characterized by SEM analysis [Fig. 7(B)] and through an inverted optical microscope (Fig. 8). Both figures show that cells adhered and proliferated in contact with the film. After $72 \mathrm{~h}$, cells already presented the typical fibroblastic morphology as well as the lamellipodia phenomenon, i.e., the connection to the surrounding fibroblast [Fig. 7(B)] [45]. Furthermore, cells physiological response to the presence of the films was also evaluated through an MTS assay. The obtained results show that the fibroblast cells viability was not affected after $72 \mathrm{~h}$ in contact with the films, demonstrating the biocompatibility of the produced materials [Fig. 7(A)]. Also, the degradation by-products during the $72 \mathrm{~h}$ did not have an acute effect on cell viability, revealing that these films can be important candidates for the intended biomedical application. It is also possible to observe in Figure 7(A) that cell viability of the tested adhesive film is higher than that of $\mathrm{K}^{-}$. Such results may be explained by the binding of MTS to the materials that may interfere with the absorbance quantification. 
(Fig. 7)

(Fig. 8)

3.8. Characterization of the antibacterial activity of the films

Bacterial infections related to the implantation of medical devices are a serious issue which can compromise the overall treatment. Therefore, the evaluation of antibacterial characteristics of the synthesized bioadhesives was performed employing two bacteria as model, S.aureus and E.coli. The first one, a gram-positive bacterium, is the most common pathogen found in biomaterial related infections [46]. The second one, assessed as gram-negative bacteria, is commonly found in human organism.

In order to verify bacteria affinity to the surface of the materials tested, SEM micrographs were acquired (Fig. 9) after a 24h incubation period. Fig. 9 shows that the films were able to avoid the biofilm formation of both strains over their surfaces. The MAA molecule has been used in other studies where it has shown to prevent the initial bacterial adhesion and biofilm formation [35].This fact may be justified by their hydrophilicity and carboxyl group that confers to this molecule a negative charge that reduces bacterial adhesion $[47,48]$.

(Fig. 9)

\section{Conclusion}

A new strategy to synthesize potential bioadhesives based on lactic acid was successfully developed. Telechelic prepolymers $\mathrm{OH}$ terminated with low molecular weight, suitable to be applied as a viscous liquid prior to photocrosslinking, were produced by direct thermal dehydration in the presence of 1,4-butanediol. These prepolymers were further functionalized 
with methacrylic anhydride. Finally curing was achieved by photopolymerization in the presence of a biocompatible photoinitiator Irgacure ${ }^{\circledR} 2959$.

The adhesive formulation developed in this study is chemically stable with a fast polymerization under controlled conditions. Preliminary results suggest this material is able to maintain the tissue substrates firmly adhered during the wound healing process, whereas it is biodegraded when no longer needed. In order to predict the body reaction to the presence of this new material, an exhaustive characterization was performed, showing promising biocompatibility and strong microbial inhibition.

Bioadhesives can potentially be applied in several parts of the body; however each tissue has its unique properties. The simple and efficient approach here reported can be used to introduce new functionalities into the biodegradable network as well as specific interaction sites, and to promote and control cell response. Therefore, tailor-made materials according to the targeted tissues and specific medical procedures can be easily produced.

\section{Acknowledgments}

The financial support from FCT for grants SFRH/BD/42245/2007 and SFRH/BPD/86338/2012 is gratefully acknowledged.The Research Grant provided to Tiago Correia CENTRO-07-0224FEDER-002014 is also recognized.The authors would like to thank 73100, Lda. for the financial support. 


\section{References}

[1] A. P. Duarte, J. F. Coelho, J. C. Bordado, M. T. Cidade, M. H. Gil, Surgical adhesives: Systematic review of the main types and development forecast, Prog. Polym. Sci. 37 (2012) 1031-1050.

[2] M. Mehdizadeh, J. Yang, Design Strategies and Applications of Tissue Bioadhesives, Macromol.Biosci.13 (2013) 271-288.

[3] P. Ferreira, J. F. J. Coelho, M. H. Gil, Development of a new photocrosslinkable biodegradable bioadhesive, Int. J. Pharm. 352 (2008) 172-181.

[4] N. Annabi, A. Tamayol, S. R. Shin, A. M. Ghaemmaghami, N. A. Peppas, A. Khademhosseini, Surgical materials: Current challenges and nano-enabled solutions, Nanotoday 9 (2014) 574-589.

[5] A. Lauto, D. Mawad, L.J.R. Foster, Adhesive biomaterials for tissue reconstruction, J. Technol. Biotechnol. 83 (2008) 464-472.

[6] N. Sheikh, A. A. Katbab, H. Mirzadeh, Isocyanate-terminal urethane prepolymer as bioadhesive base material: synthesis and characterization, Int. J. Adhes. Adhes. 20 (2000) 299304.

[7] B. Balakrishnan, M. Mohanty, P. R. Umashankar, A. Jayakrishnan, Evaluation of an in situ forming hydrogel wound dressing based on oxidized alginate and gelatin, Biomaterials 26 (2005) 6335.

[8] D. A. Wang, S. Varghese, B. Sharma, I. Strehin, S. Fermanian, J. Gorham J, et al., Multifunctional chondroitin sulphate for cartilage tissue-biomaterial integration, Nat.Mater.6 (2007) 385 . 
[9] A. Serrero, S. Trombotto, Y. Bayon, P. Gravagna, S. Montanari, L. David, Polysaccharidebased adhesive for biomedical applications: correlation between rheological behavior and adhesion, Biomacromolecules 12 (2011) 1556.

[10] L. Sanders, R. Stone, K. Webb, T. Mefford, J. Nagatomi, Mechanical characterization of a bifunctional Tetronic hydrogel adhesive for soft tissues, J. Biomed. Mater. Res. Part A $103^{\mathrm{a}}$ (2015) 861.

[11] P. J. M. Bouten, M. Zonjee, J. Bender, S. T. K. Yauw, H. v. Goor, J. C. M. Hest, R. Hoogenboom, The chemistry of tissue adhesive materials, Prog. Polym.Sci. 37 (2014) 1375.

[12] Yu, J. Hwang, T.J. Deming, Role of L-3,4-Dihydroxyphenylalanine in Mussel Adhesive Proteins , J. Am. Chem. Soc. 121 (1999) 5825-5826.

[13] B.P. Lee, J.L. Dalsin, P.B. Messersmith, Synthesis and Gelation of DOPA-Modified Poly(ethylene glycol) Hydrogels, Biomacromolecules 3 (2002) 1038-1047.

[14]A. O. Helminen, H. Korhonen, J. V. J. Seppala, Structure Modification and Crosslinking of Methacrylated Polylactide Oligomers, J. Appl. Polym. Sci. 86 (2002) 3616-3624.

[15] C. Lurtz, K. Voss, V. Hahn, F. Schauer, J. Wegmann, E. K. Odermatt, K. P. Schmitz, K. Sternberg, In vitro degradation and drug release of a biodegradable tissue adhesive based on functionalized 1,2-ethylene glycol bis(dilactic acid) and chitosan, J. Mater. Sci: Mater. Med. 24 (2013) 667-678.

[16] M. Mehdizadeh, H. Weng, D. Gyawali, L. Tang, J. Yang, Injectable citrate-based musselinspired tissue bioadhesives with high wet strength for sutureless wound closure, Biomaterials 33 (2012) 7972-83. 
[17] D. A. S.Marques, Studies on high molecular weight poly(lactic acid) synthesis. PhD Thesis, University of Coimbra (2013).

[18] D. S. Marques, M. H. Gil, C.M.S.G. Baptista, Improving Lactic Acid Melt Polycondensation: The Role of Co-catalyst, J Appl Polym Sci 128 (2013) 2145-2151.

[19] A. S. Karikari, W. F. Edwards, J. B. Mecham, T. E Long, Influence of Peripheral Hydrogen Bonding on the Mechanical Properties of Photo-Cross-Linked Star-Shaped Poly(D,L-lactide) Networks, Biomacromolecules 6 (2005) 2866-2874.

[20] P. B. O'Donnell, J. W. McGinity, Preparation of microspheres by the solvent evaporation technique, Adv. Drug. Deliv. Rev. 28 (1997) 25-42.

[21] S-M. Ho, A. M. Young, Synthesis, polymerization and degradation of poly(lactide copropylene glycol) dimethacrylate adhesives, Eur. Polym. J. 42 (2006) 1775-1785.

[22] P. Dobrzynski, J. Kasperczyk, K. Jelonek, M. Ryba, M. Walski, M. Bero, Application of the lithium and magnesium initiators for the synthesis of glycolide, lactide, and $\varepsilon$-caprolactone copolymers biocompatible with brain tissue, J. Biomed. Mater. Res. 79 (2006) 865-873.

[23] J. S. Wiggins, M. K. Hassan, K. A. Mauritz, R. F. Storey, Hydrolytic degradation of poly(D,L-lactide) as a function of end group: Carboxylic acid VS hydroxyl, Polymer 47 (2006) 1960-1969.

[24] M. C. Tanzi, P. Verderio, M. G. Lampugnani, M. Resnati, E. Dejana, E. Sturani, Cytoxicity of some catalysts commonly used in the synthesis of copolymers for biomedical use, J. Mater. Sci: Mater. Med. 5 (1994), 393-396. 
[25] C. G. Williams, A. N. Malika, T. K Kima, P. N. Mansonb, J. H. Elisseef, Variable cytocompatibility of six celllines with photoinitiators used for polymerizing hydrogels and cell encapsulation, Biomaterials 26 (2005), 1211-1218.

[26] J.M.C. Santos, D. S. Marques, P. Alves, T. R. Correia, I. J. Correia, Cristina M. S. G. Baptista, P. Ferreira, Synthesis, functionalization and characterization of UV-curable lactic acid based oligomers to be used as surgical adhesives, React. Funct. Polym. 94 (2015) 43-54

[27] J. C. Liu, I. Y. Rad, F. Sunb, J. W. Stansbury, Photo-reactive nanogels as a means to tune properties during polymer network formation, Polym. Chem. 5 (2014), 227-233.

[28]J. C. Liu, J. W. Stansbury, RAFT-mediated control of nanogel structure and reactivity: Chemical, physical and mechanical properties of monomer-dispersed nanogel compositions, Dental Materials 30 (2014), 1252-1262.

[29] J. Seppala, H. Korhonen, R. Hakala, M. Malin, Photocrosslinkable Polyesters and Poly(esteranhydride)s for Biomedical Applications, Macromol. Biosci. 11 (2011) 1647-1652.

[30] M.P. Ribeiro, P.I. Morgado, S.P. Miguel, P. Coutinho, I.J. Correia, Dextran-based hydrogel containing chitosan microparticles loaded with growth factors to be used in wound healing, Mat. Sci. Eng. C. 33(5) (2013) 2958-2966.

[31] P. H. Castilho, T.R. Correia, M. T. Pessoa de Amorim, I. C. Escobar, J.A. Queiroz, I.J. Correia, A.M. Morão, Modification of microfiltration membranes by hidrogel impregnation for pDNA purification, J. Appl. Polym. Sci. 132 (2015) 41610.

[32] M. P. Ribeiro, A. Espiga, D. Silva, P. Batista, J. Henriques, C. Ferreira, J. C. Silva, J. P. Borges, E. Pires, P. Chaves, Development of a new chitosan hidrogel for wound dressing, Wound repair and regeneration, 17 (2009) 817-824. 
[33] K.T. Nguyen, J.L. West, Photopolymerizable hydrogels for tissue engineering applications, Biomaterials 23(22) (2002) 4307-4314.

[34] P. Alves, R. Cardoso, T.R. Correia, B.P. Antunes, I.J. Correia, P. Ferreira, Surface modification of polyurethane films by plasma ultraviolet light to improve haemo compatibility for artificial heart valves, Colloid. Surface B. 113 (2014) 25-32.

[35] P. Ferreira, A. Carvalho, T.R. Correia, B.P. Antunes, I.J. Correia, P. Alves, Functionalization of polydimethylsiloxane membranes to be used in the production of voice prostheses, Sci. Technol. Adv. Mater.14 (2013) 055006.

[36] S. Jarmelo, D.A.S. Marques, P. N. Simões, R. A. Carvalho, C. M. S. G. Baptista, C. AraujoAndrade, M. H. Gil, R. Fausto, Experimental (IR/Raman and 1H/13C NMR) and Theoretical (DFT) Studies of the Preferential Conformations Adopted by L-Lactic Acid Oligomers and Poly(L-lactic acid) Homopolymer, J PhysChem B 116 (2012) 9-21.

[37] J. L. Espartero, I. Rashkov, S. M. Li, N. Manolova, M. Vert, NMR analysis of low molecular weight poly(lactic acid)s, Macromolecules 29 (1996) 3535-3539.

[38] C. Decker, Photoinitiated Crosslinking Polymerisation, Prog. Polym.Sci. 21 (1996) 593.

[39] C. Decker, The use of UV Irradiation in Polymerization, Polymer International 45 (1998) 133.

[40] C. S. Proikakis, N. J. Mamouzelos, P. A. Tarantili, A. G. Andreopoulos, Stability of D,LPoly (lactic acid) in Aqueous Solutions, J. Appl. Polym. Sci. 87 (2003) 795-804.

[41] C. S. Proikakis, N. J. Mamouzelos, P. A. Tarantili, A. G. Andreopoulos, Swelling and hydrolytic degradation of poly(D,L-lactic acid) in aqueous solutions, Polym. Degrad. Stab.91 (2006) 614-619. 
[42] F. Hejda, P. Solar, J. Kousal, Surface Free Energy Determination by Contact Angle Measurements - A comparison of Various Approaches, Proceedings of Contributed Papers Part III (2010) 25-30.

[43] P. Ferreira, A. F. M. Silva, M. I. Pinto, M. H. Gil, Development of a biodegradable bioadhesive containing urethane groups, J. Mater. Sci: Mater. Med.19 (2008) 111-120.

[44] J.M. Reinke, H. Sorg, Wound repair and regeneration, Eur. Surg. Res. 49(1) (2012) 35-43.

[45] S. P. Miguel, M.P. Ribeiro, H. Brancal, P. Coutinho, I.J. Correia, Thermo responsive chitosan-agarose hydrogel for skin regeneration, Carbohyd. Polym. 111 (0) (2014) 366-373.

[46] A. C. L. Batista, G. C. Dantas, J. Santos, R. V. S. Amorim, Antimicrobial Effects of Native Chitosan against Opportunistic Gram-negative Bacteria, Microbiology Journal 1 (3) (2011) 105112.

[47] G. Gratzl, C. Paulik, S. Hild, J. P. Guggenbichler, M. Lackner, Antimicrobial activity of poly(acrylic acid) block copolymers, Mat. Sci. Eng. C. 38 (2014) 94-100.

[48] A. Ehara, M. Torii, S. Imazato, S. Ebisu, Antibacterial activities and release kinetics of a newly developed recoverable controlled agent-release system, J. Dent. Res. 79(3) (2000) 824828. 


\section{Captions}

Fig.1.Schematic representation of the lactic acid prepolymer synthesis, functionalization and crosslinking reaction.

Fig. 2. ${ }^{1} \mathrm{H}$ NMR spectra of the lactic acid telechelic prepolymer (bottom) and functionalization with MAA (top).

Fig. 3. ATR-FTIR spectra of the lactic acid prepolymer, functionalization with MAA (macLAMAA) and photocrosslinked product (netLA-MAA).

Fig. 4. Tan $\delta$ traces at $1 \mathrm{~Hz}$ and $10 \mathrm{~Hz}$ obtained from the photocrosslinked product.

Fig. 5.TGA of lactic acid based oligomers, adhesive formulation and the resulting photocrosslinked product.

Fig. 6. Bioadhesive weight loss against hydrolysis time, in PBS solutions at $37^{\circ} \mathrm{C}$.

Fig. 7.A) Evaluation of the cellular activity after 24, 48 and $72 \mathrm{~h}$ - netLA-MAA; positive control $(\mathrm{K}+)$; negative; control $\left(\mathrm{K}^{-}\right)$. Each result is the mean \pm standard error of the mean of three independent experiments. B) SEM images of cell adhesion and proliferation on netLA-MAA materials surface during $72 \mathrm{~h}$.

Fig.8.Microscopic photographs of human fibroblasts cells seeded in the presence of netLA.MAA films (*) for 24, 48 and $72 \mathrm{~h}$ of incubation, originalmagnification $100 \times$.

Fig. 9.SEM images of E.coli and S.aureus seeded in the presence of netLA-MAA film.

Table 1.Characterization of prepolymer, functionalization and photocrosslinked product. 


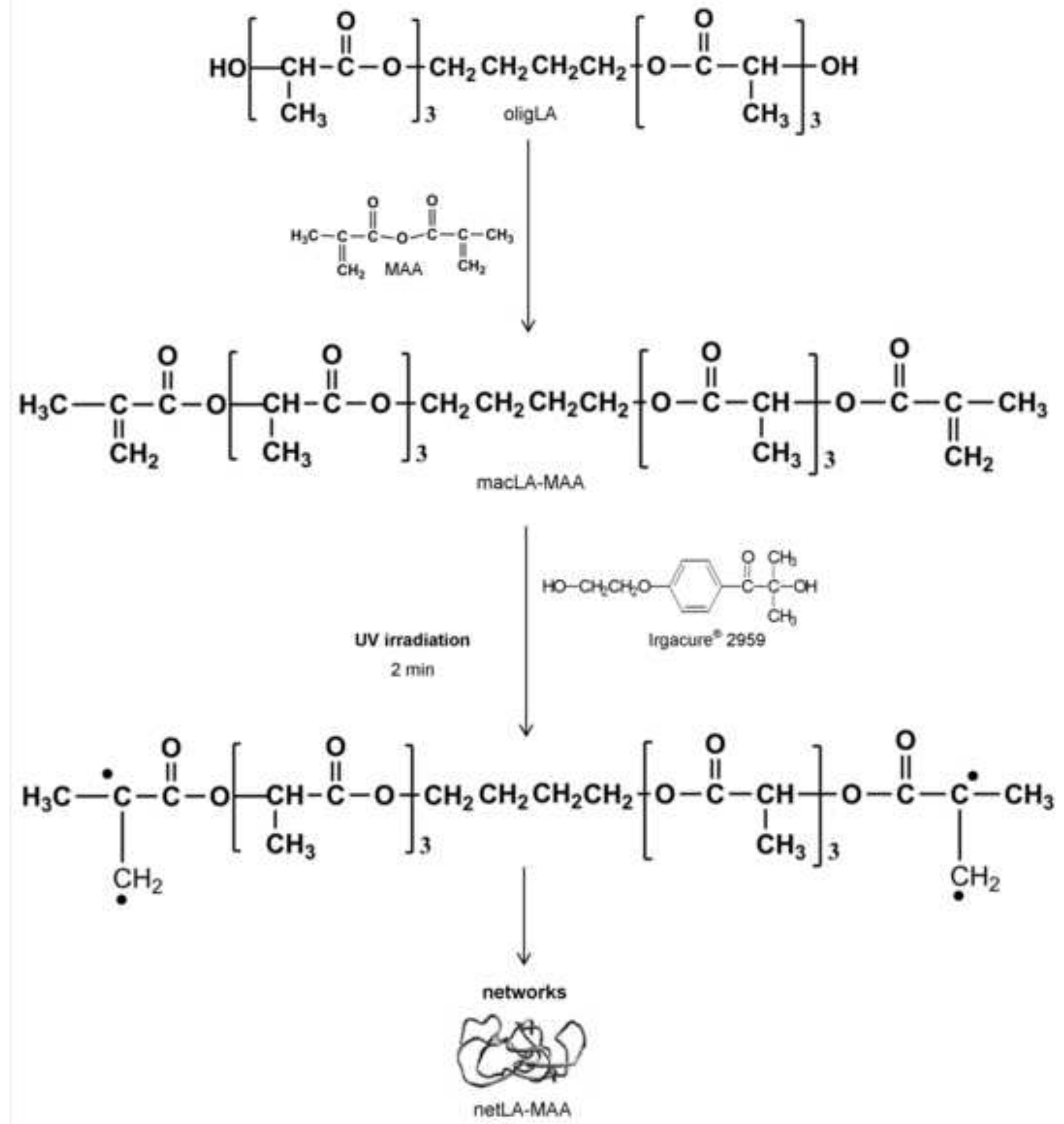




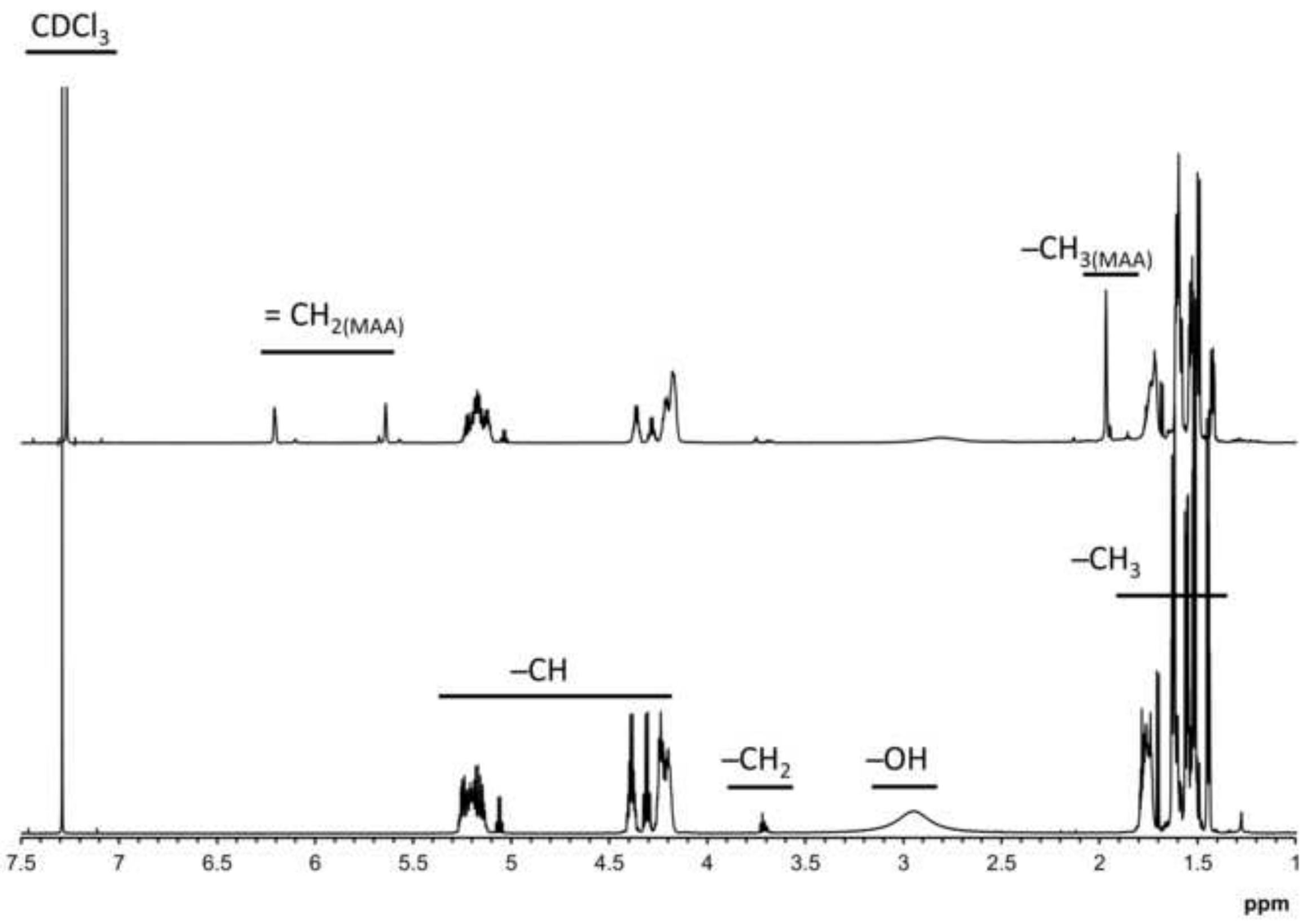




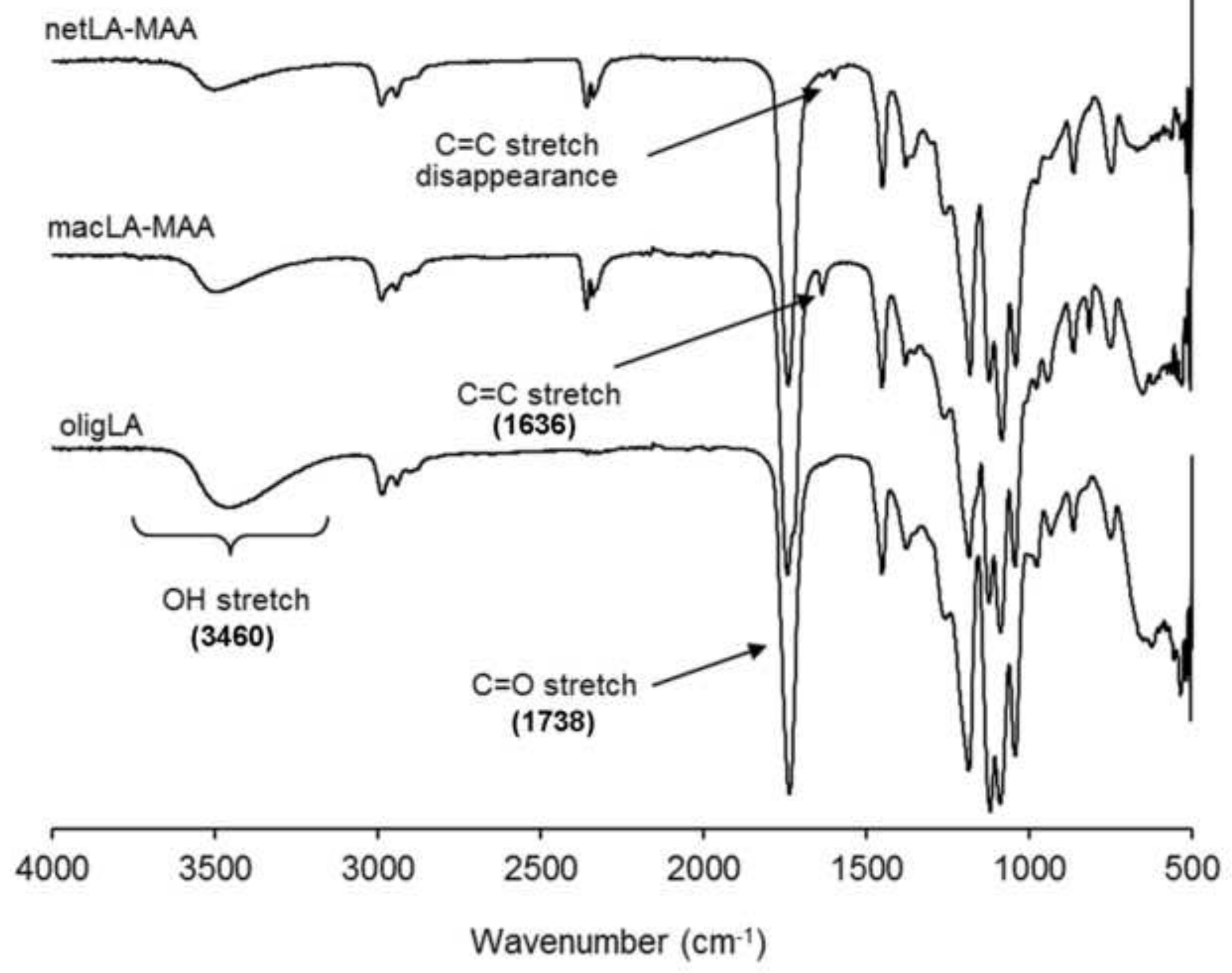




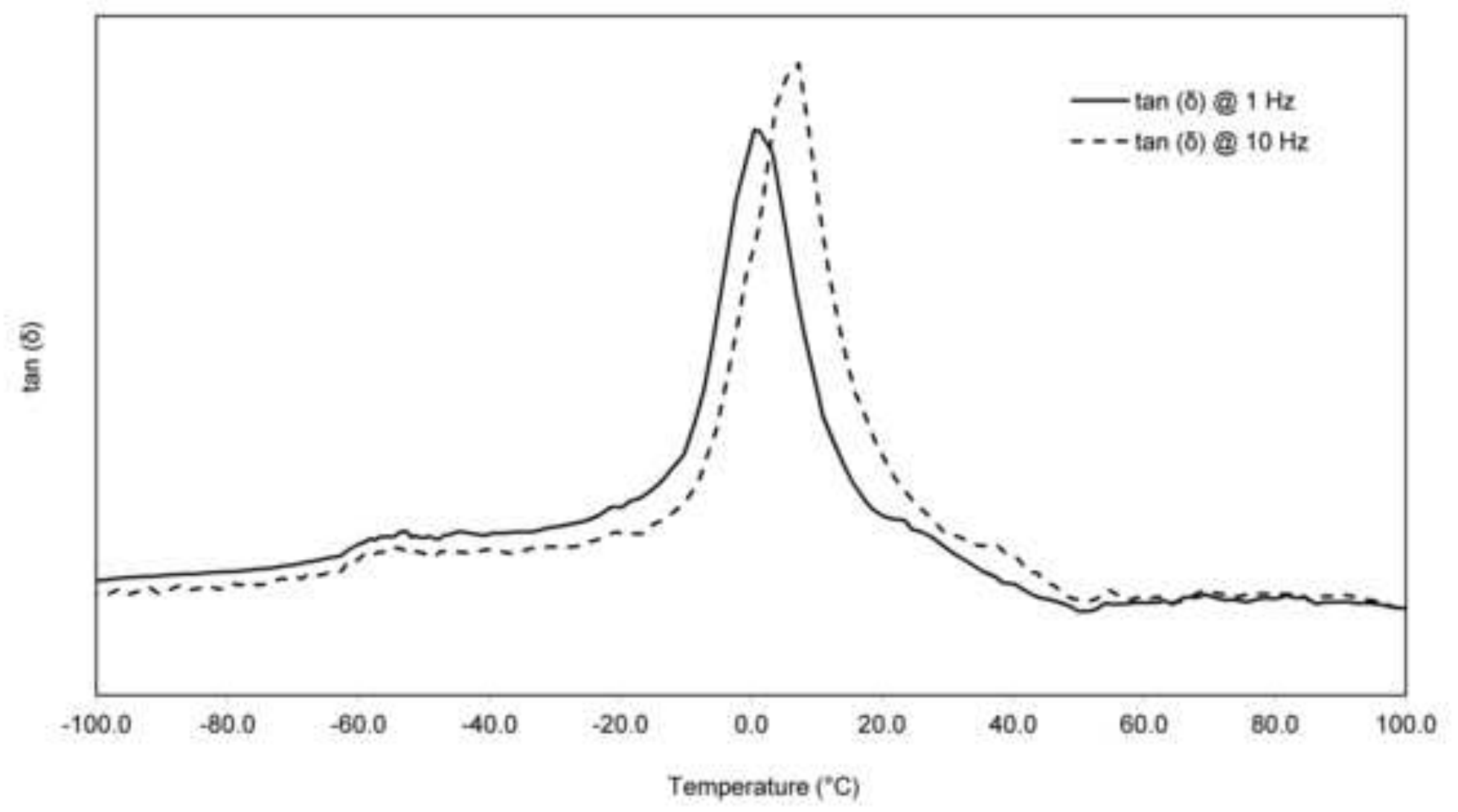




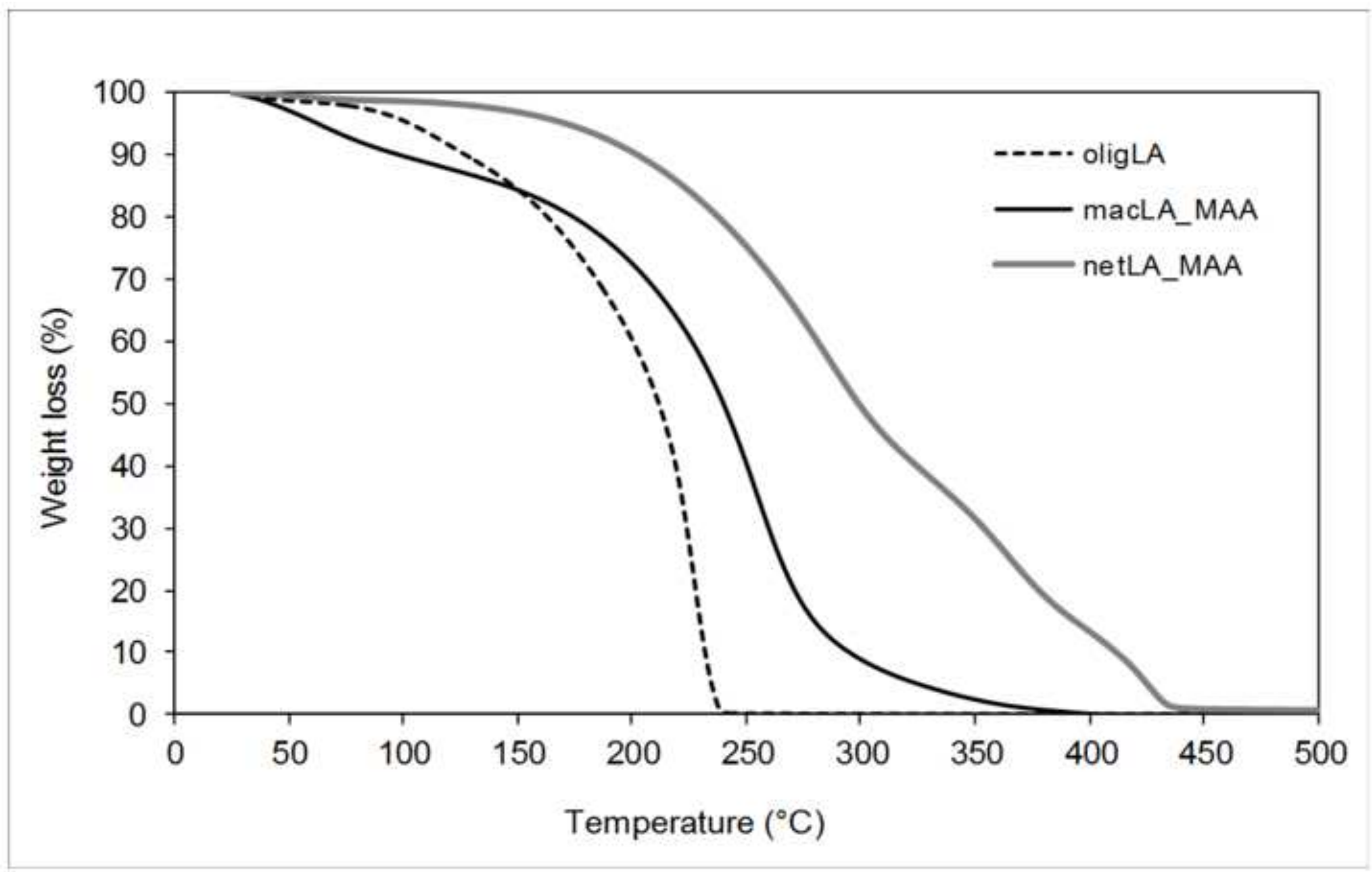




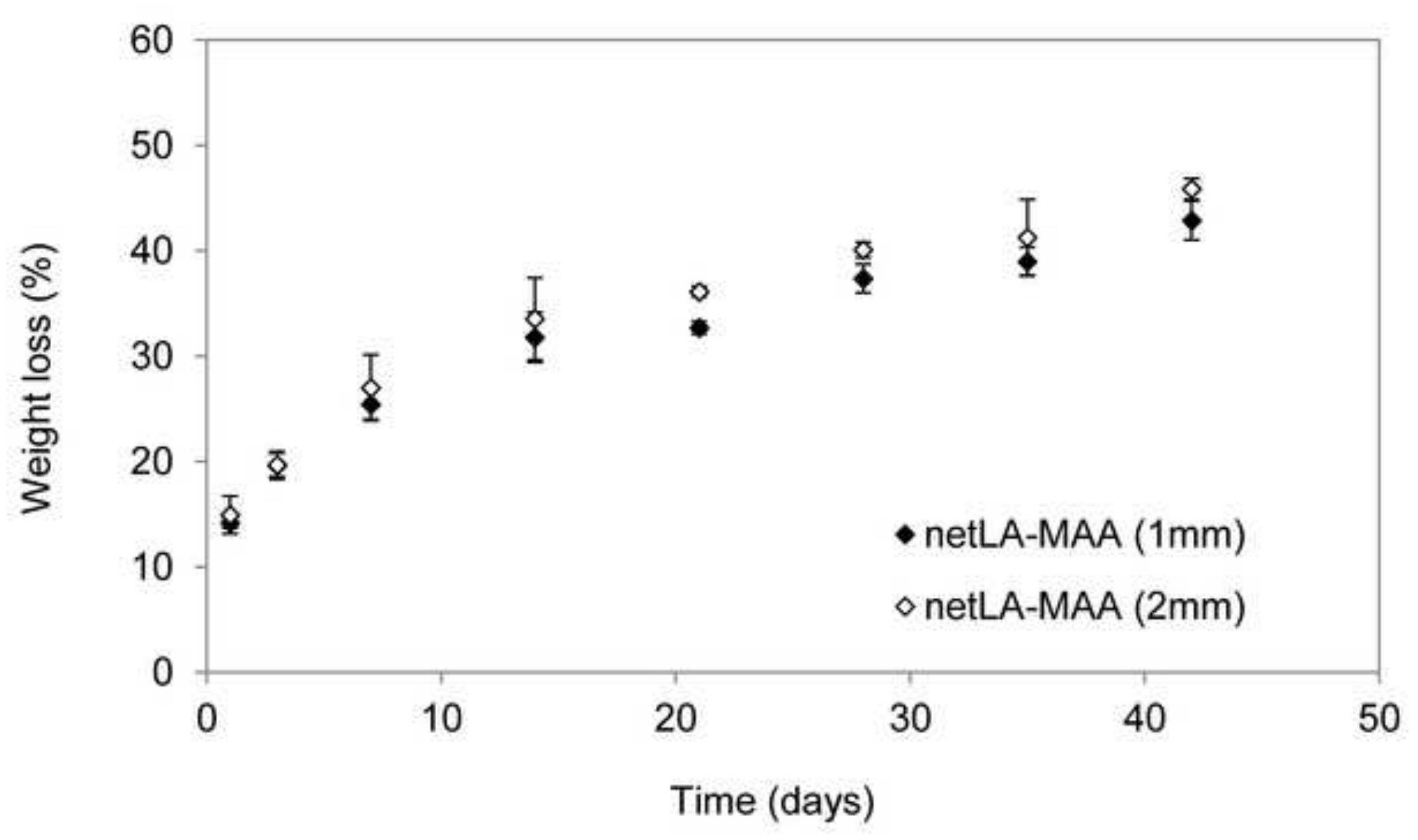




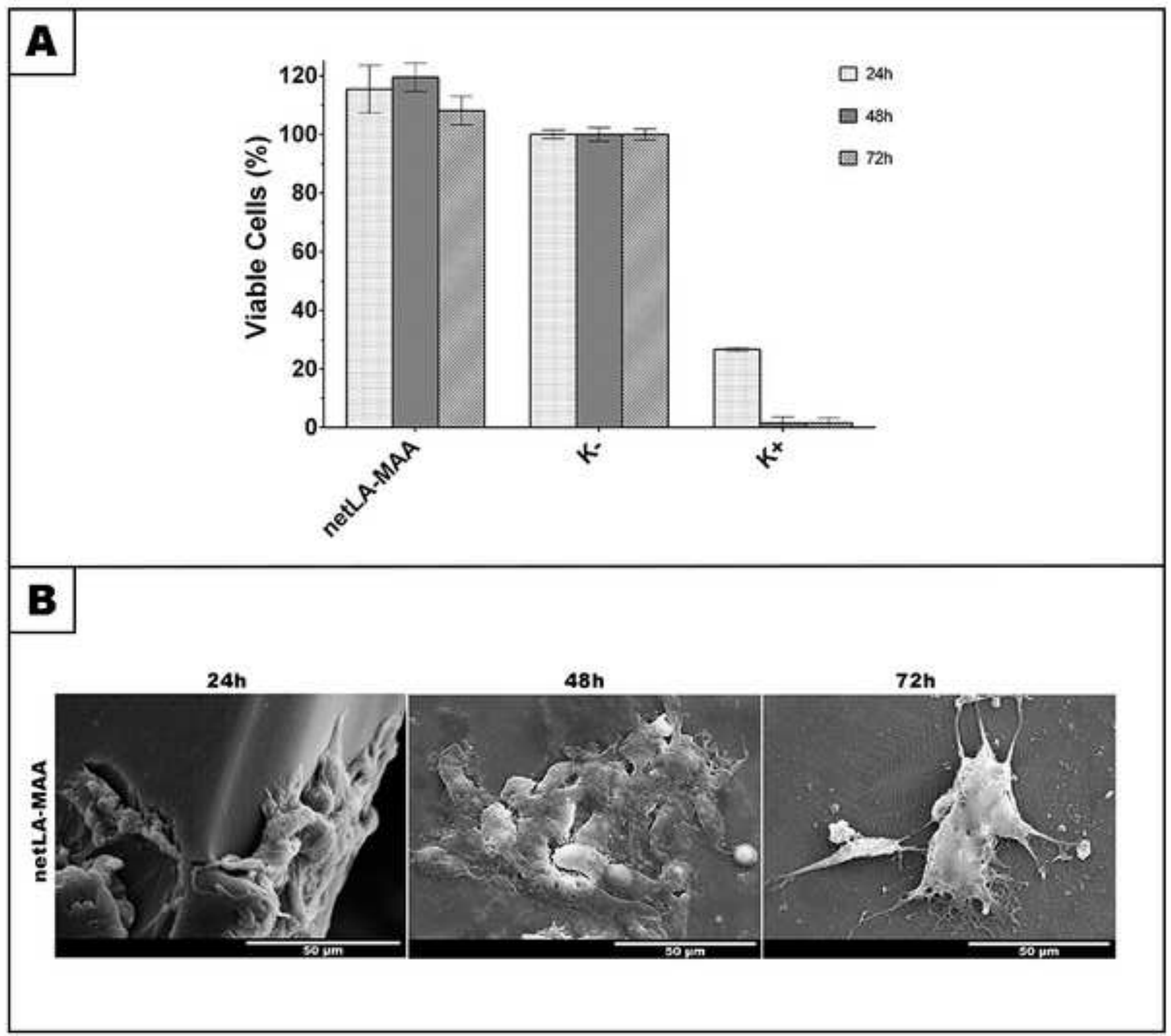




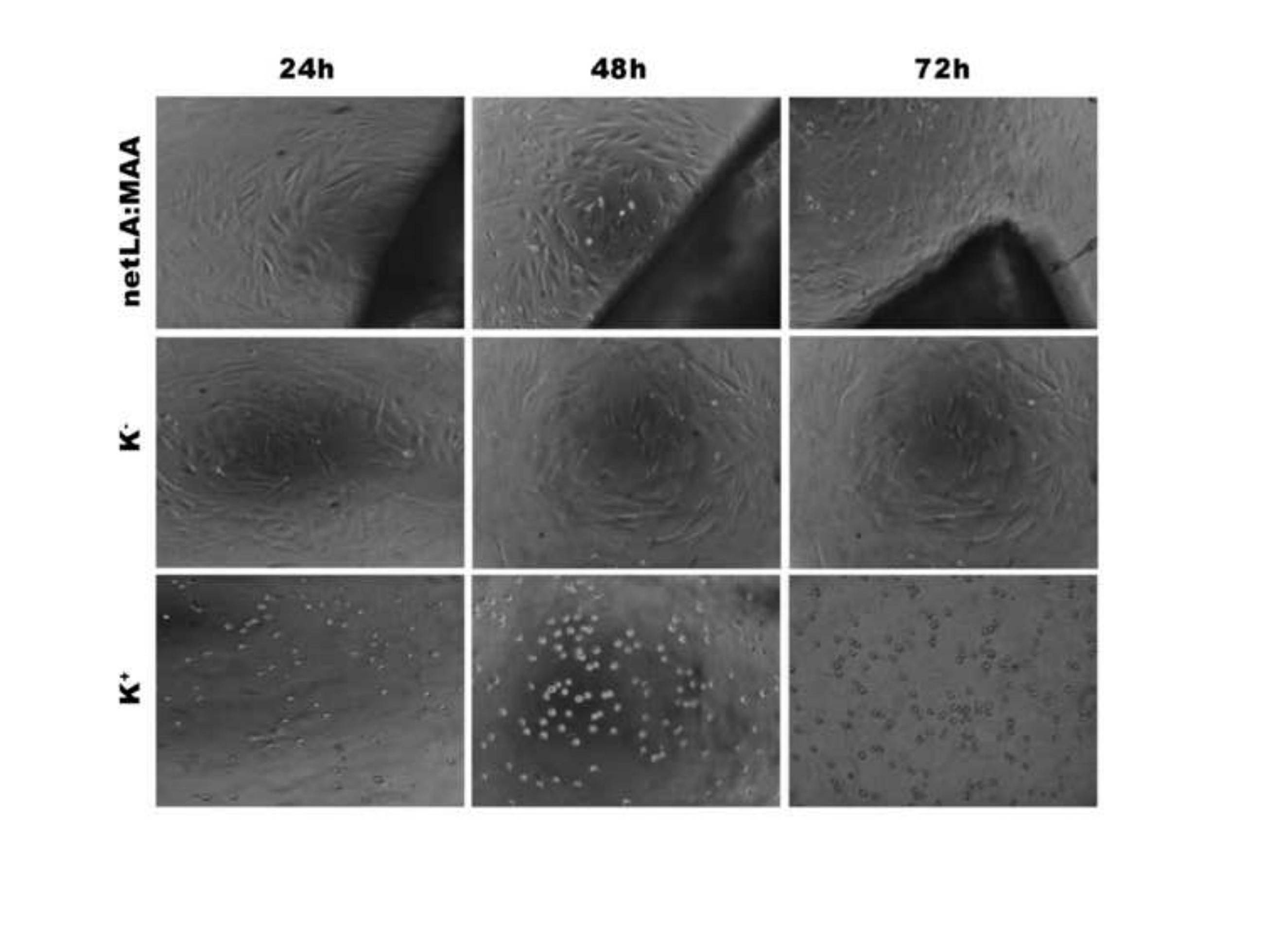

$24 h$

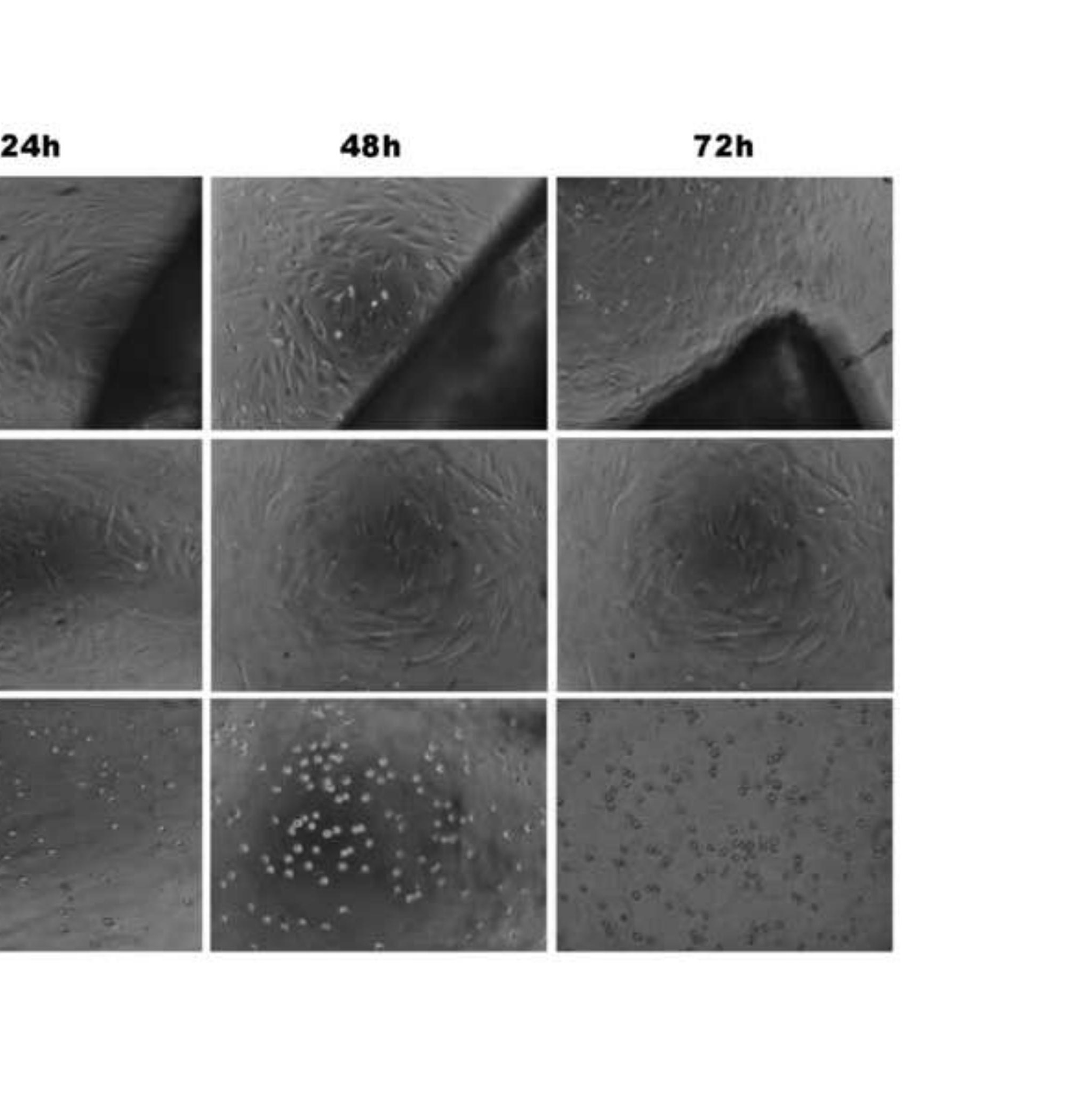

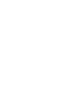

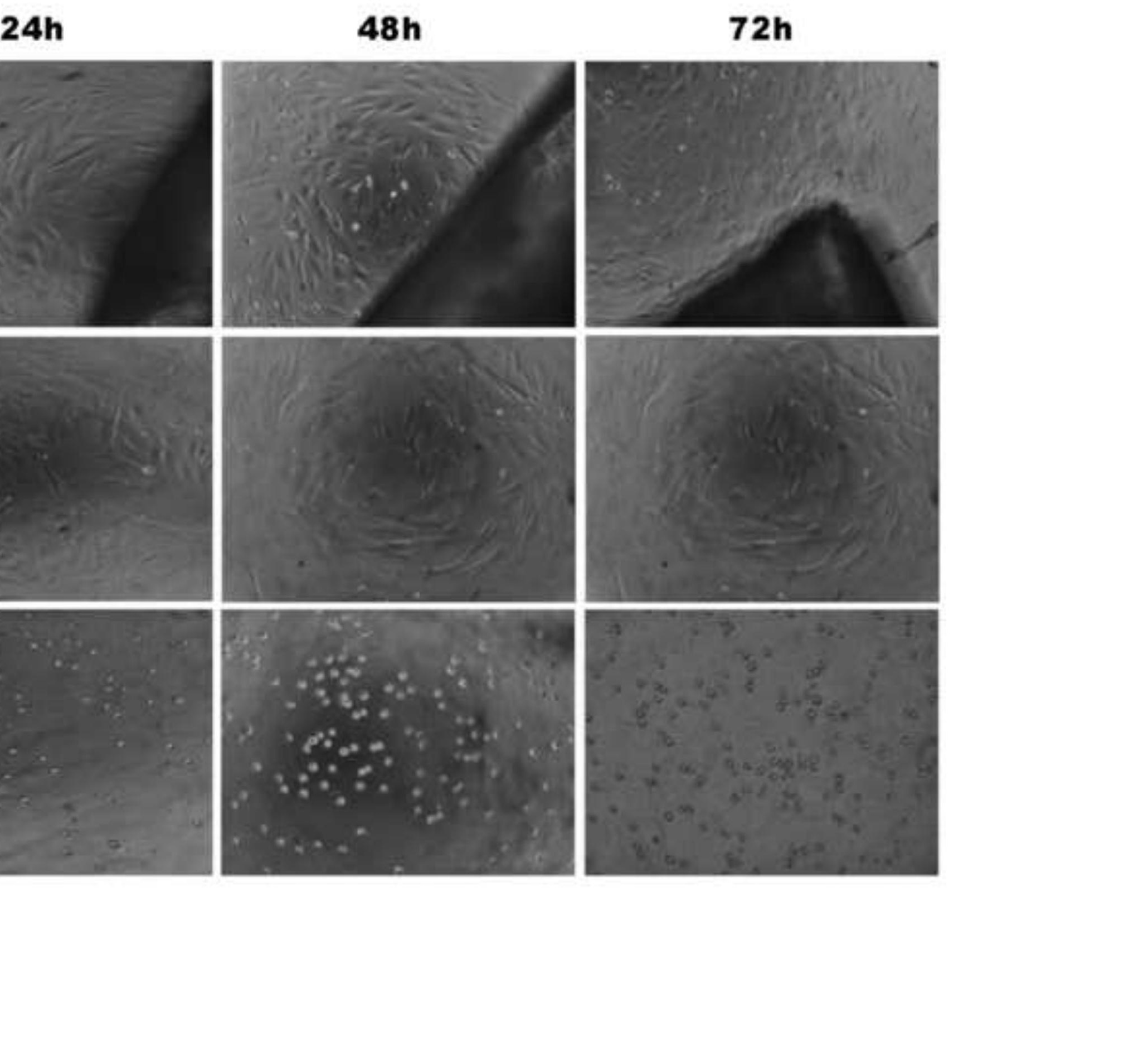

8
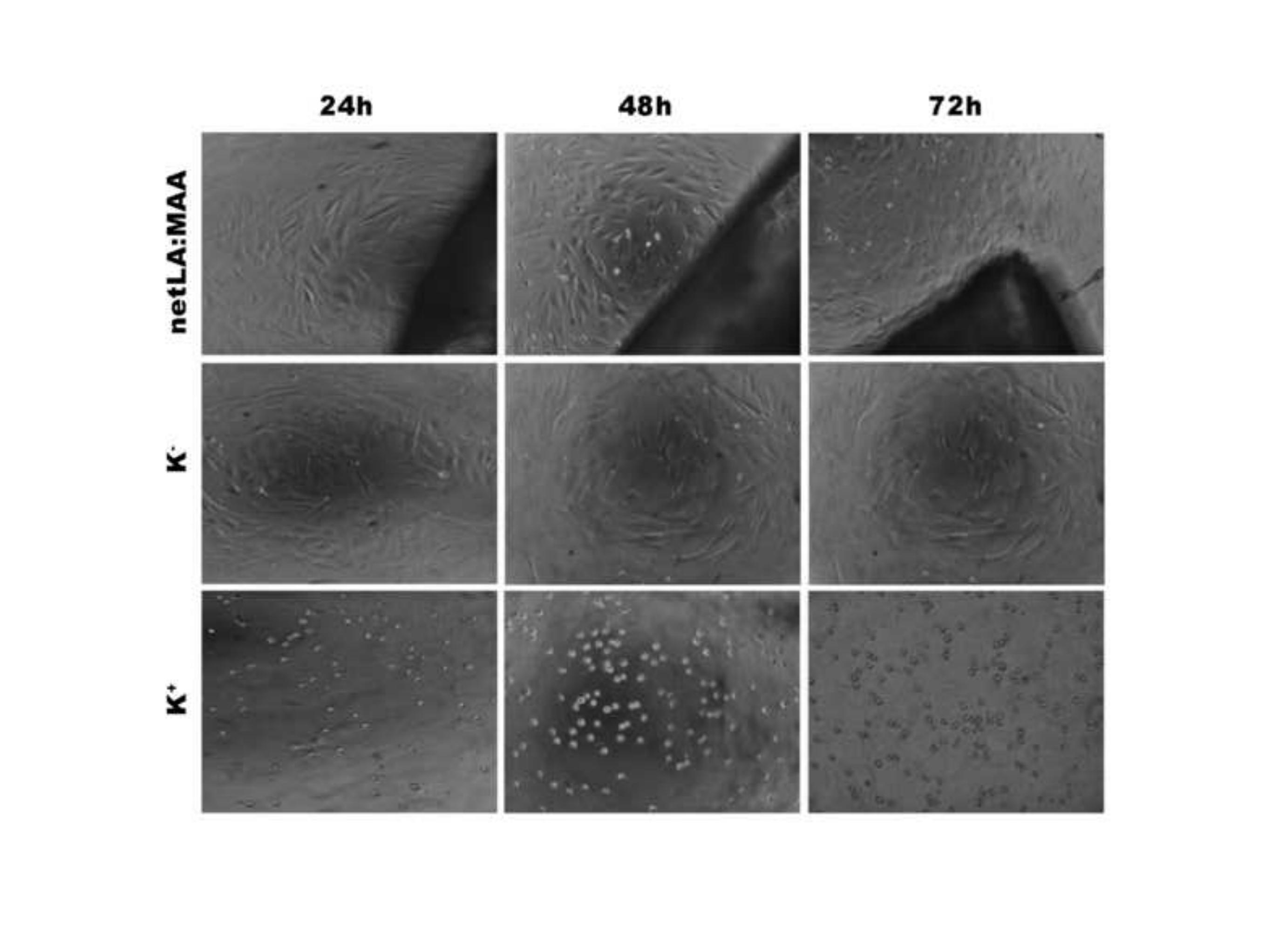
< Table 1 >

\begin{tabular}{ccccc}
\hline Product & $\begin{array}{c}M n \text { target } \\
(\text { g.mol-1) }\end{array}$ & $\begin{array}{c}\mathbf{T g}_{\text {DMTA }} \\
\left({ }^{\mathbf{O}} \mathbf{C}\right)\end{array}$ & $\begin{array}{c}\text { Curing Time } \\
(\text { min })\end{array}$ & $\begin{array}{c}\text { Swelling } \\
(\%)\end{array}$ \\
\hline oligLA & 500 & - & - & - \\
macLA-MAA & 654 & - & - & - \\
netLA-MAA & - & 1 & 2 & 10 \\
\hline
\end{tabular}



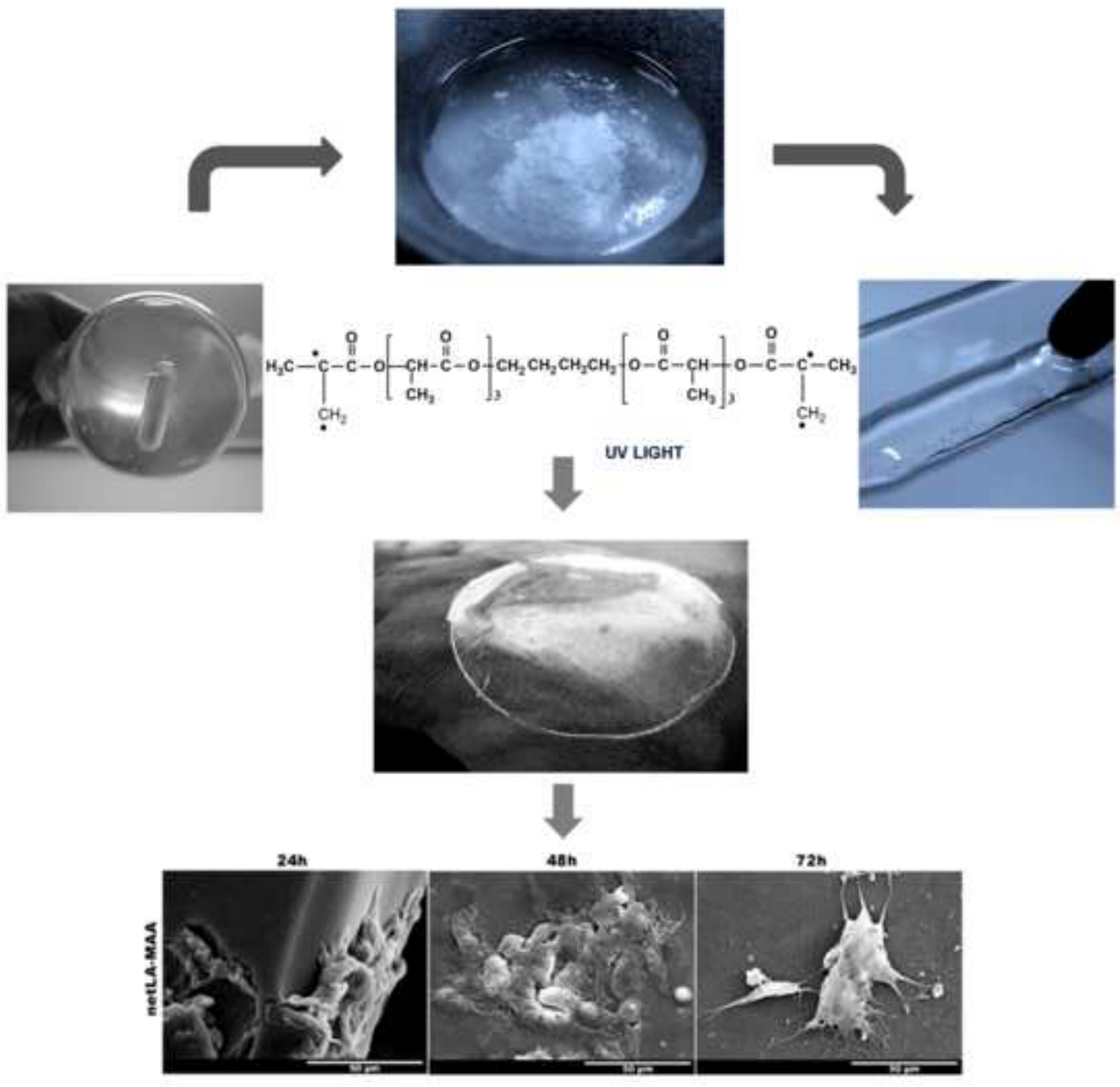

$24 \mathrm{~h}$

$46 \mathrm{~h}$

$72 \mathrm{~h}$
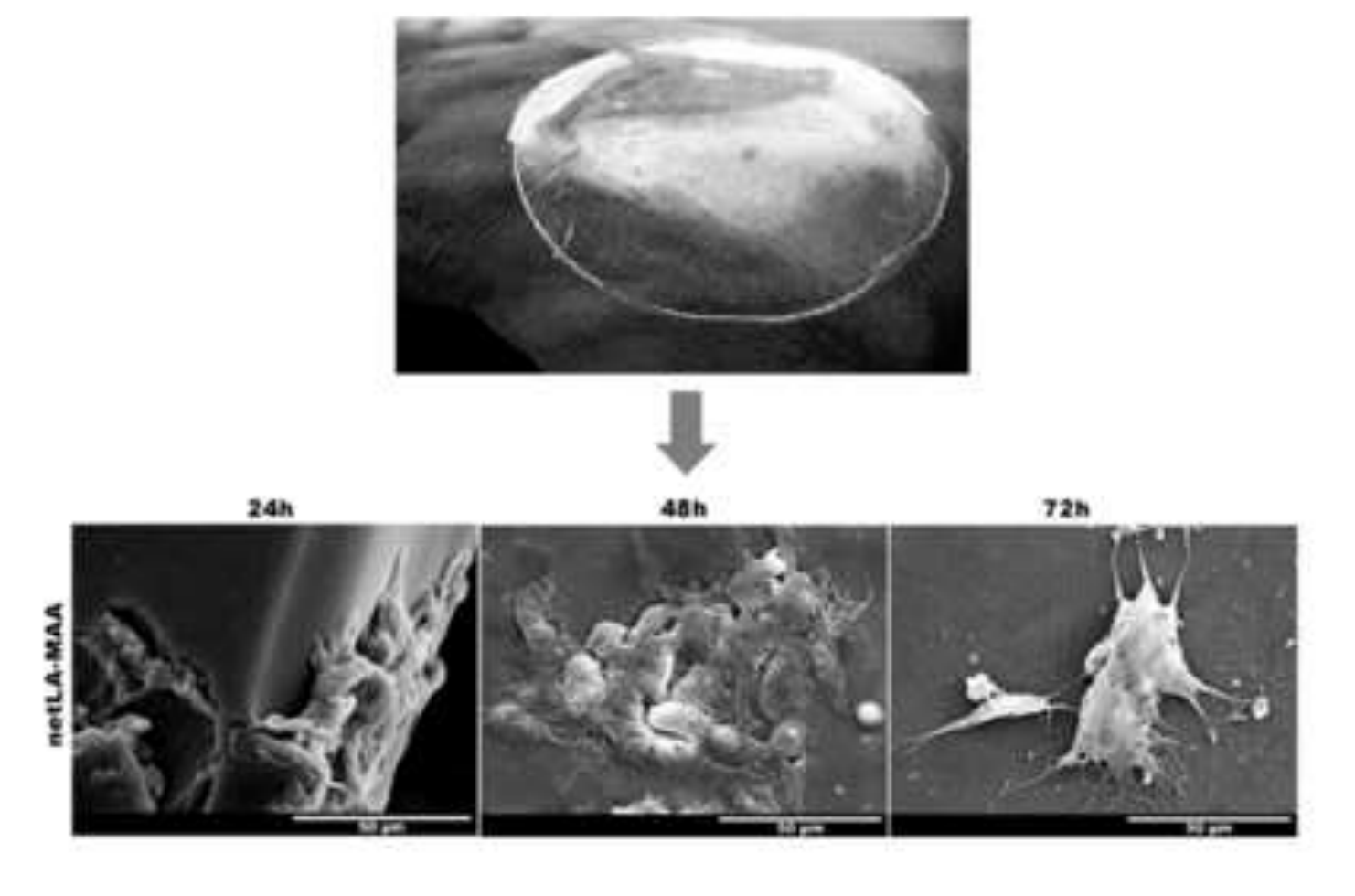